\title{
Application of SWAT Model for Estimating Runoff in Upper Nile River Basin
}

\author{
Rebecca Sultana ${ }^{1}$, Shashwat Dhungana ${ }^{2}$ and Nimnee Bhatta ${ }^{3}$ \\ ${ }^{1}$ Southern University Bangladesh, Bangladesh. \\ ${ }^{2}$ Nepal Development Research Institute, Nepal. \\ ${ }^{3}$ Katholieke Universiteit Leuven (IUPWARE), Belgium.
}

\section{ARTICLE INFO}

Keywords:

Hydrological models; calibration; validation; sensitivity; $C N 2$

\begin{abstract}
Hydrological models have been used to analyze the hydrological processes and availability of water in different watersheds. It is one of the most significant aspects of water resources management and development programme to use different hydrological models for predicting the flow of river basins. Calibration and validation of the developed hydrological model is also important so that the model users can be confident while estimating the flow of the watershed. In this study, a semi-distributed hydrological model was developed for 0.176 million km2 Upper Blue Nile river basin using Soil and Water Assessment Tool (SWAT). The applicability of SWAT was assessed for rainfall- runoff simulation in Upper Blue Nile basin. The model was calibrated and validated using 10 years of discharge data. Model calibration and sensitivity analysis were performed with sequential uncertainty fitting (SUFI-2), which is one of the programs interfaced with SWAT, in the package SWAT-CUP. The most and least sensitive parameters were CN2 (curve number) and GW_DELAY (ground water delay time) respectively. Performance of the model was evaluated based on Nash Sutcliff Efficiency (NSE) and Coefficient of Determination (R2) which were 0.71 and 0.66 respectively for calibration. Overall, the model demonstrated good performance in producing the patterns and trend of the observed discharge which assures the suitability of the SWAT model for future scenario analysis. Uncertainty analysis of the SWAT model of upper Blue Nile basin, consideration of other parameters and incorporating more flow data from other stations within the basin is recommended for future studies.
\end{abstract}

\section{Introduction}

It is widely agreed that a reliable hydrologic prediction is imperative to plan, design and manage water resources activities (Tiwari and Chatterjee, 2010). Various modelling tools, techniques and software (like MIKE SHE, SHETRAN, HEC HMS, SWAT) are available in the present context (Amr Fleifle, Ralf Ludwig, \& Markus Disse, 2017; Chu Xuefeng \& Steinman Alan, 2009; Nasr et

\footnotetext{
$\square$ Corresponding Author E-Mail Address: emasultana09@gmail.com
} 
al., 2007). The developments in computing technology and recent advances in the availability of digital datasets and the use of geographic information systems (GIS) for water resources management have revolutionized the study of hydrologic systems (Jain \& Sharma, 2014). Hydrologic models ranging from empirical to physically based distributed parameters have been developed to estimate runoff and sediment yield during the past three decades.

The Soil and Water Assessment Tool (SWAT), an integrated river basin model, has been widely applied to simulate hydrological flows (A. van Griensven, P. Ndomba, F. Kilonzo, \& S. Yalew, 2012; Abbaspour et al., 2007; Nasr et al., 2007). Free availability and ready applicability through the development of geographic information system (GIS) based interfaces, and easy linkage to sensitivity, calibration and uncertainty analysis tools are highlighted as the reason behind its popularity (A. van Griensven et al., 2012). SWAT, developed by the United States Department of Agriculture - Agricultural Research Services (USDA - ARS), integrates the spatial analysis capabilities of GIS with the temporal analysis simulation abilities of hydrologic models. It is a small watershed to river basin-scale model to simulate the quality and quantity of surface and ground water and predict the environmental impact of land use, land management practices, and climate change (Amr Fleifle et al., 2017). It takes Digital Elevation Model (DEM), landuse/landcover, soil map and hydro-meteorological data as its inputs.

The Upper Blue Nile basin has a varying topography, precipitation and temperature patterns (Melesse, Abtew, Setegn, \& Dessalegne, 2011). Spatial distribution of annual rainfall over the basin is highly variable with up to $2049 \mathrm{~mm}$ in southern tip compared to just over $794 \mathrm{~mm}$ in the north-eastern tip (Abtew, Melesse, \& Dessalegne, 2009). The high variability in climate and paucity of necessary data in the basin underpins the difficulties in estimating hydrology in the region. Further, the basin is faced with problems relating to land degradation, limited amount of developed energy sources, and inadequate crops production. Use of hydrological models to better understand complex systems as such could be ideal to improve water resources and land management practices (Amr Fleifle et al., 2017). This is challenging because hydrological analyses in the basin have perennially suffered from limited data availability and lack of study attempting to identify good approaches to model dominant hydrological processes based on available data (Tegegne, Park, \& Kim, 2017).

Various studies have used the SWAT for a multitude of problems in the Upper Nile basin countries (Abtew et al., 2009; Amr Fleifle et al., 2017; Dile et al., 2018; Tegegne et al., 2017). However, a critical review of 20 peer reviewed research that demonstrated satisfactory to very good results using the SWAT model highlighted several paper using unrealistic parameter values while several others containing losses in hydrological mass balances that might not be justified, and some failed to report these components (A. van Griensven et al., 2012). The main recommendation was to provide more details on the model set-up, the parameters and outputs to allow for a more robust evaluation of these methods. Therefore, the first objective of this study was to build on the recommendation provided and use the SWAT model to estimate runoff in the Upper Blue Nile basin providing specific information about model-set up, the parameters and outputs.

In addition, distributed hydrological modelling is subject to large uncertainties. Walker et al. (2003) defined uncertainty as "any deviation from the unachievable ideal of completely deterministic knowledge of the relevant system". In hydrological simulations, uncertainties could arise from the imperfect knowledge and modelling of initial conditions, and errors in the model structure and parameters of the hydrological model (Van den Bergh \& Roulin, 2016). To define and quantify these uncertainties, various analysis techniques have been prepared for watershed models like Bayesian 
inference methods, such as: the Markov chain Monte Carlo (MCMC) method, generalized likelihood uncertainty estimation (GLUE), parameter solution (ParaSol), and sequential uncertainty fitting (SUFI-2) (ROSTAMIAN et al., 2008). Various studies have used SUFI-2 algorithm for calibration and uncertainty analysis of their SWAT models (Abbaspour et al., 2007; Setegn, Srinivasan, \& Dargahi, 2008; Talebizadeh et al., 2010) and have reported improvement in model performance. Therefore, the second objective of this study was to make use of SUFI-2 algorithm for a combined calibration and uncertainty analysis and make comparison with manual calibration.

\section{Methods and Materials}

\subsection{Study Area}

Eleven riparian countries share the Nile basin which is the lifeline for 238 million of people. The water of Nile river basin has been used by upstream and downstream residents for domestic, agricultural, industrial and other purposes such as hydropower, ecosystem etc. (Dile et al., 2018). The length of the Nile river is $6,670 \mathrm{~km}$ with a watershed area of 3.2 million $\mathrm{km}^{2}$ (El Bastawesy, Gabr, \& Mohamed, 2015).

The White Nile and the Blue Nile forms the Nile river. Upper Blue Nile is the biggest tributary of Nile river and largest river basin in Ethiopia depending on the flow volume. Ethiopia's 17\% area is comprised by it which is $176000 \mathrm{~km}^{2}$ out of $1100,000 \mathrm{~km}^{2}$ (D. Conway, 2000). The mean annual discharge of this area is $1536 \mathrm{~m}^{3} / \mathrm{sec}$ (Mengistu et al., 2014). The climate is dependent on the elevation. It is normally tropical at lower elevation and temperate on higher elevation (D. (Climatic R. U. Conway, 1997). The basin has mono-modal type rainfall. From 1990-1998 the annual rainfall ranged between 1150-1750 mm/year. The average rainfall was $1420 \mathrm{~mm} /$ year (Tekleab, Mohamed, \& Uhlenbrook, 2013). The average yearly potential evapotranspiration varies spatially and high. It varies from 1000-1800 mm/ year (D. Conway, 2000). The mean annual temperature was estimated $18.5^{\circ} \mathrm{C}$ with some seasonal variation (less than $3^{\circ} \mathrm{C}$ ) (Mengistu et al., 2014). 
Figure 1: Blue Nile River basin

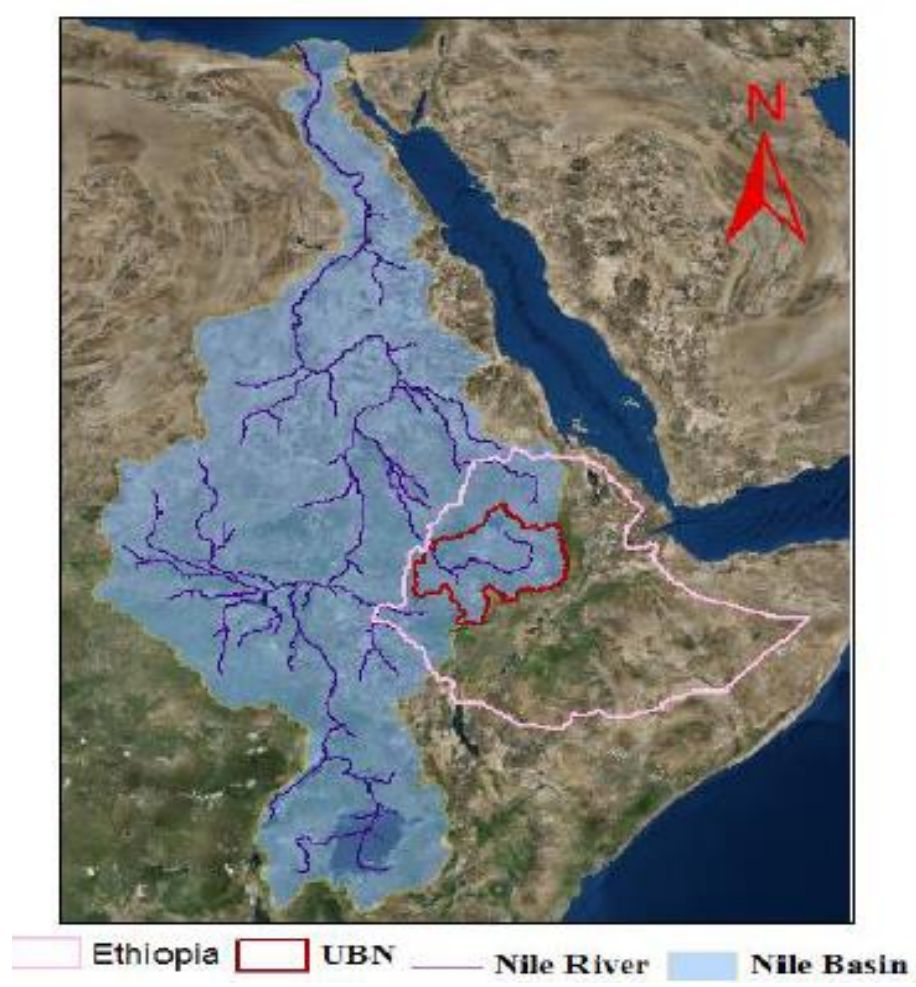

Leptosols and Vertisols are the dominant types of soil in the study area (Kim \& Kaluarachchi, 2009). The geology of the basin is characterized by basalt rocks, which are discovered in the highland of Ethiopia. On the contrary, metamorphic rocks and basement rocks cover the lower part of Ethiopia (Tekleab et al., 2013).

\subsection{Methodology}

For this catchment, different data sets were used in the study. Food and Agricultural Organization of United Nation (FAO-UNESCO) developed the $1000 \mathrm{~m}$ resolution soil map which was used in ArcSWAT. The map was collected from SOIL-FAO database. Vegetation and their parameters were calculated using the $1000 \mathrm{~m}$ resolution land use map which was collected from the database of USGS-United State Geological Survey. Time series for daily rainfal and water flow covering the period from January 1961 to December 2002 were available for developing, calibrating and validating the model.

\subsubsection{Model Setup}

For this catchment, different data sets were used in the study (Table 1). 
Table 1: Necessary data to develop the model

\begin{tabular}{|c|c|c|}
\hline GIS Data & Meteorological Data & Observed Data \\
\hline DEM & Rainfall & \multirow{2}{*}{ Flow data } \\
\hline Land use & Wind & \multicolumn{1}{|c|}{} \\
\hline Soil type & Temperature & \\
\cline { 2 - 2 } & Relative humidity & \\
\hline
\end{tabular}

The model built up was done in the following four steps:

\subsubsection{Watershed Delineation}

Watershed delineating was done by loading topography, contour and slope from the DEM (90 m $\mathrm{x} 90 \mathrm{~m}$ ) followed by burning in the river shape file and defining the stream flow direction and accumulation. The outlet for whole watershed was defined and then the sub basin parameters were calculated. Finally, 25 sub basins were created. The delineated watershed map is represented in Figure 2.

Figure 2: Watershed delineation in Arc Swat

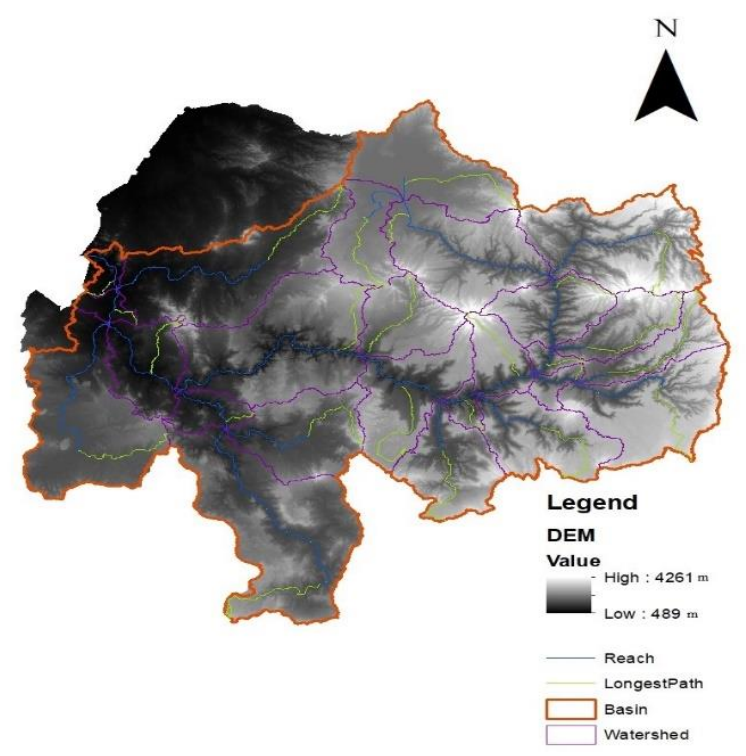

\subsubsection{HRU Analysis}

In this step, the catchment was divided into 299 HRU's based on the distribution of land use and soil classes. At first the land use and soil map were loaded and for slope, multiple slope with three slope classes were defined and then they were reclassified. Multiple HRU's with threshold of $10 \%$, $0 \%$ and $25 \%$ for land use, soil and slope class respectively were selected for HRU's analysis. It reduces the computational costs of simulations by adding same types of soil and land use areas into a single unit. 


\subsubsection{Writing Input Tables}

After creating the sub basins and HRU's, input files were created by using the available weather data. Then input tables were created with default values which are used for further analysis in the Upper Blue Nile SWAT model.

\subsubsection{Model Simulation}

Finally, a time period of 01 Jan 1968 to 31 Dec 1972 with one-year warm up period was used to run the model with default values.

\subsubsection{Sensitivity Analysis}

Sensitivity analysis is an effective way to study the behavior of parameter and for determining how the model input has an influence on model output and its uncertainty. It is as important as calibration process because it allows user to determine the most sensitive parameters and to have an idea which parameter needs to be calibrated in order to reduce the model uncertainty. Sensitivity analysis can further be subdivided into two categories based on the use of the automatic tools (manual vs automated sensitivity analysis ) and the number of analyzed parameters (one at a time vs global sensitivity analysis) (Brouziyne et al., 2017)

For this study, SWAT CUP 2012 was used to perform sensitivity analysis. Global sensitivity analysis was carried out for 26 different SWAT input parameters. A new project was created by using SUIF2 calibration method. The Par_inf_txt was defined by providing the 26 parameters that need to be estimated along with the min and max range. Other information such as observation data, start and end of simulation, Nash Sutcliffe (NS) with a threshold of 0.2 etc. were defined and executed for 800 simulations.

\subsubsection{Manual Calibration}

Calibration is a process to adjust model parameter in order to predict the model results as closely to observation. It is an important step for analyzing conceptual model. Manual calibration is performed by the user to reduce the prediction uncertainty by changing the parameter to the desired condition and then comparing with model output with observed data for the same condition. However, it can take a longer time to complete even a single model calibration depending on the size of watershed, simulation period and spatial resolution (P. W. Gassman et al., 2007). Hence, for the effective and successful manual calibration, expert judgment along with the extensive knowledge about the catchment are very important to decide which parameter to adjust and how much to adjust to obtain reasonable result. Then, goodness of fit between model results and observation was determined by different objective functions like Nash-Sutcliffe coefficient (NSE), determination coefficient (R2) etc.

\subsubsection{Automatic Calibration}

Automatic calibration is a process to improve the quality of the model that is calibrated manually by obtaining a better objective function for simulated values. In this step, final parameter values obtained from the manual approach were used as an initial value for auto calibration in the SWAT Cup. Swat Cup 2012 is a freeware auto-calibration program which allows the use of various algorithm for optimization of SWAT results in hydrological modeling. It can be used for sensitivity analysis, calibration, validation and uncertainty analysis of SWAT models and also to visualize watershed. However, in this study, SWAT-Cup was applied only for sensitivity analysis and automatic calibration using a SUFI2 optimization program by representing uncertainties from 
various sources. To calibrate a model in SWAT CUP, it is important to select objective function on which the iteration will estimate the best parameter and best simulation flow. So, NashSutcliffe model efficiency coefficient (NSE) was used as an objective function to compare model results with observation values.

\subsubsection{Model Validation}

Calibration is followed by validation. Validation is a process to determine whether the developed model for a specific study area yields acceptable simulation for any time period. It involves running a model using parameters that were determined during the calibration process (manual and automatic), and comparing the predicted value to observed data for a different time period. For this purpose, time period of 1974-1978 with one year as warm up was used for validating both the result obtained from manual as well as automatic calibration. Finally, results were analyzed with objective function and also graphically by observing simulated flows with observation flows.

\section{Results and Model Evaluation}

\subsection{Sensitivity Analysis}

Out of the 26 parameters, only few parameters that are most sensitive for flows were determined based on p-test and t-test. A t-test determines the relative significance of each parameter and ranks the parameter based on the absolute values (i.e. larger the absolute values, more sensitive the parameter is) whereas p-test determines the sensitivity of the parameter (i.e. value closes to zero has more significance) (GRIENSVEN, 2017). The most sensitive parameters are shown below in the Table 2:

Table 2: Sensitive parameters

\begin{tabular}{|c|c|c|c|}
\hline Parameters & t-stat & $\begin{array}{c}\text { Fitted } \\
\text { Value }\end{array}$ & $\begin{array}{c}\text { Min-Max } \\
\text { Value }\end{array}$ \\
\hline CN2 & -18.73 & -0.072 & $-0.5-0.25$ \\
\hline SOL_K & -18.00 & 1341.25 & $0-2000$ \\
\hline CH_K2 & 17.91 & 79.78 & 0.150 \\
\hline ALPHA_BF & -13.06 & 0.00063 & $0-1$ \\
\hline SLSUBBSN & 12.05 & 65.21 & $10-150$ \\
\hline HRU_SLP & -10.03 & 0.0094 & $0-1$ \\
\hline CH_N2 & 7.41 & -0.224 & $-0.5-0.25$ \\
\hline SOL_AWC & 6.02 & 0.431 & $-0.25-0.6$ \\
\hline EPCO & 4.36 & 0.524 & $0.1-1$ \\
\hline RCHRG_DP & 3.69 & 0.183 & $0-1$ \\
\hline ESCO & -2.77 & 0.993 & $0.8-1$ \\
\hline GW DELAY & 2.69 & 25.37 & $1-60$ \\
\hline
\end{tabular}




\subsection{Initial Model Result}

Simulation was done for 5 years (1968-1972) with 1-year warmup year. After running the simulation, initial simulated values were obtained. There is a huge difference between the observed and simulated outflow which states the overestimation of the parameters in Figure 3. The NSE value is -5.81 which shows poor performance of the model. That is why manual calibration was done, to obtain a satisfactory objective function.

Figure 3: Model outflow with default parameters

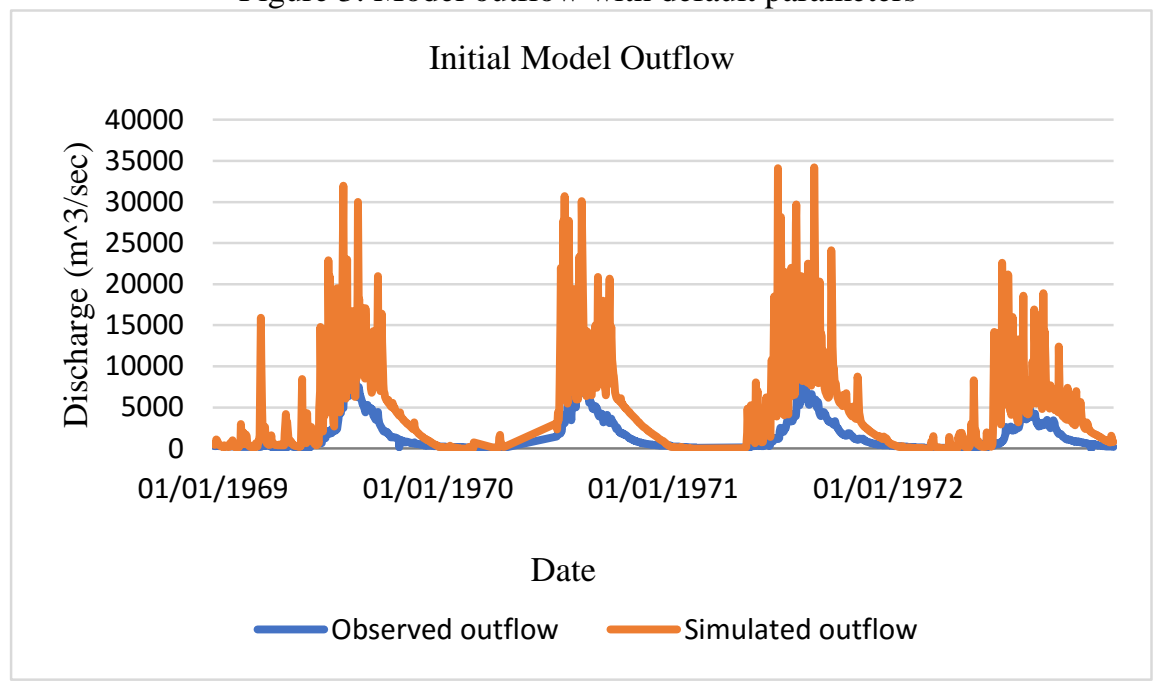

\subsection{Model Calibration/Validation}

\subsubsection{Manual Calibration Results}

At the beginning Curve number, CN2 parameter was selected for the optimization of the model result. With the help of manual calibration helper $\mathrm{CN} 2$ values of all 25 sub-basins were reduced to $15 \%$ from the default value. After running the model with changed CN2 values, the model was still overestimating simulated total flow which is shown in Figure 4. The calibrated CN2 value ranges between 35-98. With decreasing $\mathrm{CN} 2$ value the surface runoff decreases. But infiltration, base flow and recharge increases. As a result, the total outflow increases. Also, Nash-Sutcliffe efficiency is -3.498 , which proves poor performance of the model and suggests further improvement. So, our purpose was to reduce the value of baseflow more to match the simulated flow with the observed one. 
Figure 4: Manual calibration with changed CN2 value

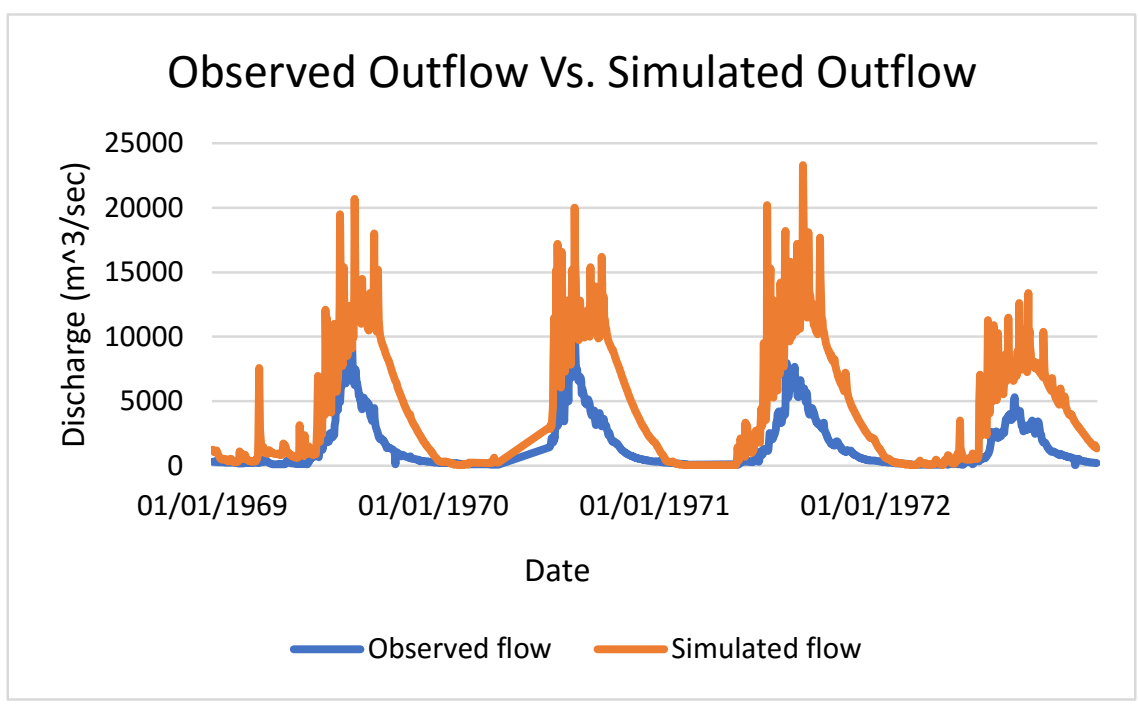

After the first iteration, some other parameters were taken into consideration. By changing the, Sol_AWC, ESCO, CH_K2, CH_N2, CANMX, RCHRG_DP values, the model was calibrated again. Alpha_BF and GW delay were also modified to calibrate the baseflow. GW_Delay is defined as the time which water takes to enter into the shallow aquifer by going out from the soil profile (Me, Abell, \& Hamilton, 2015). The range of GW delay is from 0-500 days. It affects the width and time of the peak (Ahl, Woods, \& Zuuring, 2008). Alpha_BF is also sensitive in discharge simulation. When this value decreases it shifts the lag time ahead. Aquifer percolation coefficient also increases recharge in deep aquifer with its increasing value. Water can again go to the unsaturated zone running from shallow aquifer. Groundwater revap coefficient (GW_REVAP) was increased from 0.02 to 0.17 , so that less amount of water transfer to the root zone. Water going to deep aquifer as recharge can be influenced by RCHRG_DP, Soil evaporation compensation factor (Huber, 2015). ESCO decreases the run-off, evapotranspiration and baseflow when its value reduces. If soil available water (Sol_AWC) is larger, it holds more water which results in lower surface runoff and percolation (Jha, 2011). Hydraulic conductivity of the soil (SOL_K) was increased to reduce the movement of water through the soil. On the contrary, effective hydraulic conductivity (CH_K2) was also increased to $75 \mathrm{~mm} / \mathrm{hr}$. After changing these parameters, the model efficiency improved.

At last, changing the parameter values increased the NSE and improved the model efficiency. From the graph given below (Figure 5), it is observed that the observed and model outflow has better match. The observed and simulated discharge matched quite well from 1971-1972. However, there is some under-estimation of simulated discharge in some of the days during high flows. The NSE value is 0.71 which falls within the range (0-1). 
Figure 5: Manual calibration with final parameter values

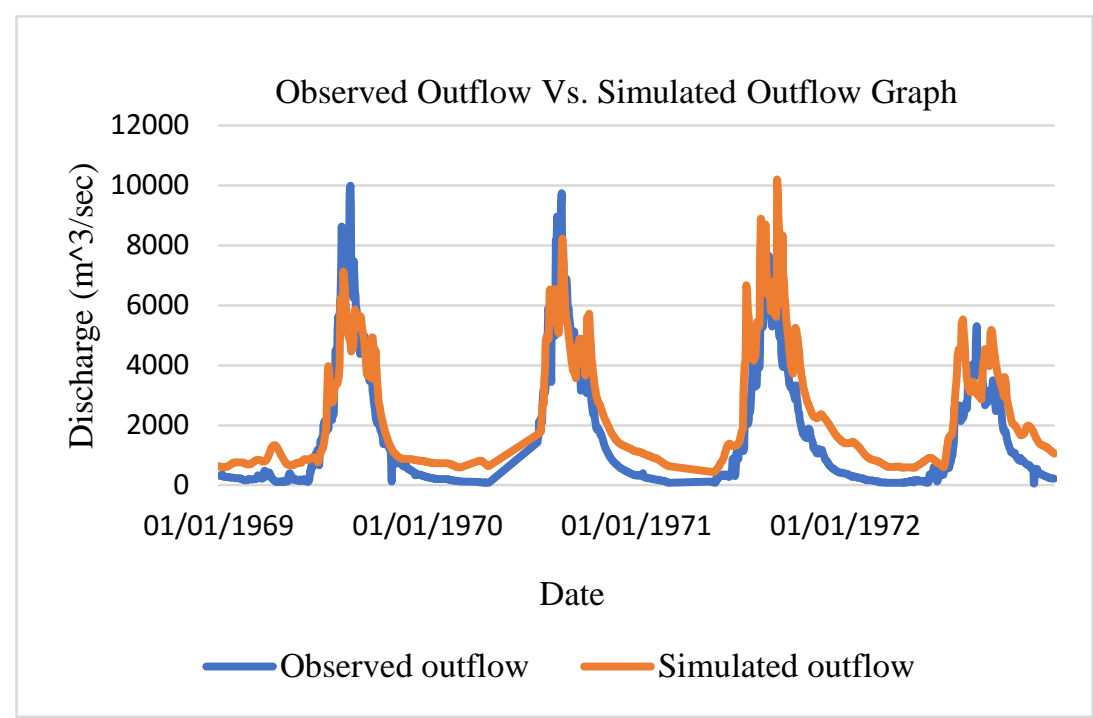

Table 3: Adopted parameter value

\begin{tabular}{|c|c|c|}
\hline Parameter & Default Value & Adopted Value \\
\hline CN2 & 83 & 70.38 \\
\hline Alpha_BF & 0.048 & 0.35 \\
\hline Sol_AWC & 0.17 & 0.34 \\
\hline GW delay & 31 & 100 \\
\hline RECHRG DP & 0.05 & 0.2 \\
\hline ESCO & 0.95 & 0.9 \\
\hline CH_K2 & 0 & 75 \\
\hline CH_N2 & 0.014 & 0.1 \\
\hline Gwqmn & 1000 & 1700 \\
\hline Gw REVAP & 0.02 & 0.17 \\
\hline SOL K & 25.56 & 24.74 \\
\hline CANMX & 0 & 3 \\
\hline
\end{tabular}

\subsubsection{Manual Validation Results}

Validation is the process where it is shown that the model is able to give approximate accurate results. After manual calibration, validation was done with the calibrated model for a different period of time. The validation period was focused on the year (1974-1978) and 1 year was included as a warm up year. After running the model, model outflow and observed flow were compared which is represented in Figure 6. 
Figure 6: Manual validation with final parameter values

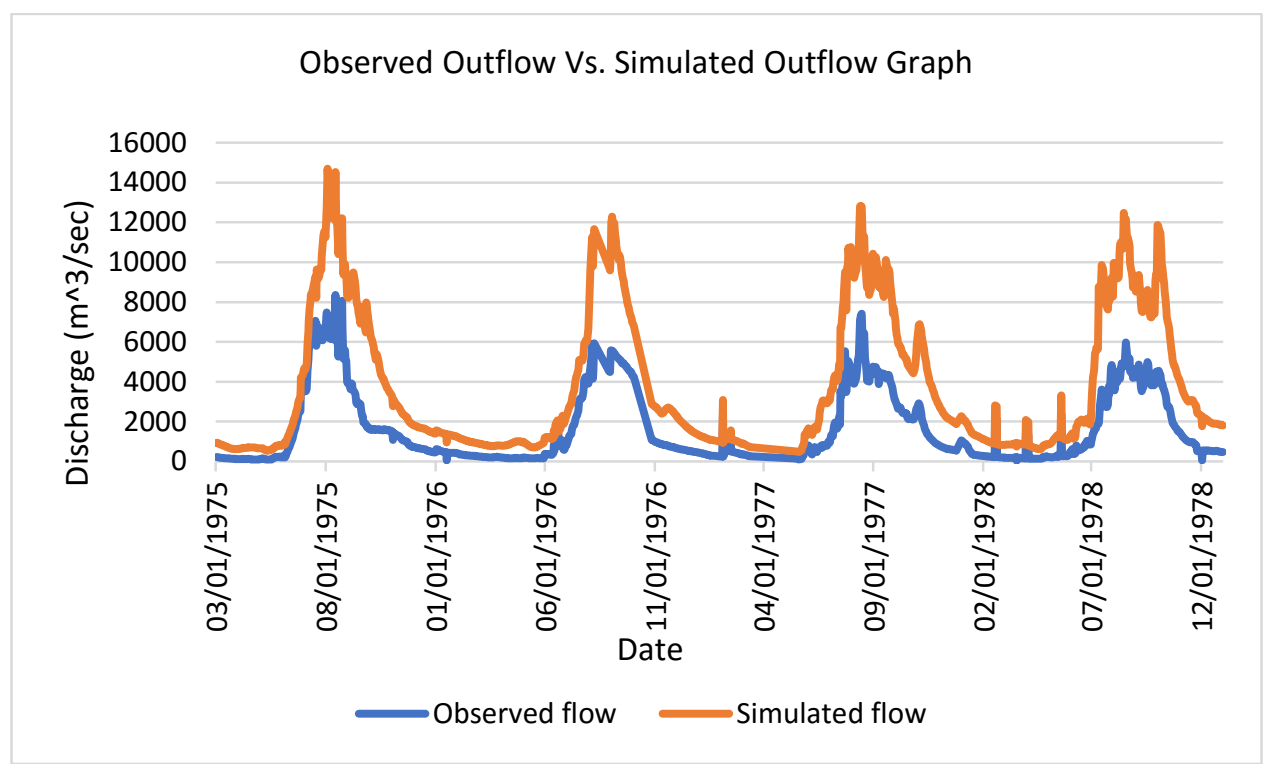

In the validated model simulated total outflow was higher than the observed flow. However, the NSE values was 0.79 . In manual calibration, only some parameters were chosen. That is why automatic calibration is needed to get more accurate simulation.

\subsubsection{Automatic Calibration Results:}

After providing all the parameter input, first iteration was performed for only 10 simulations to obtain an idea about parameter range and by manually adjusting some parameter, the model was calibrated with around 2000 simulations till 8 iterations unless we obtained satisfactory value for specified NSE objective function.

Figure 7: Final automatic calibration with 10 simulations

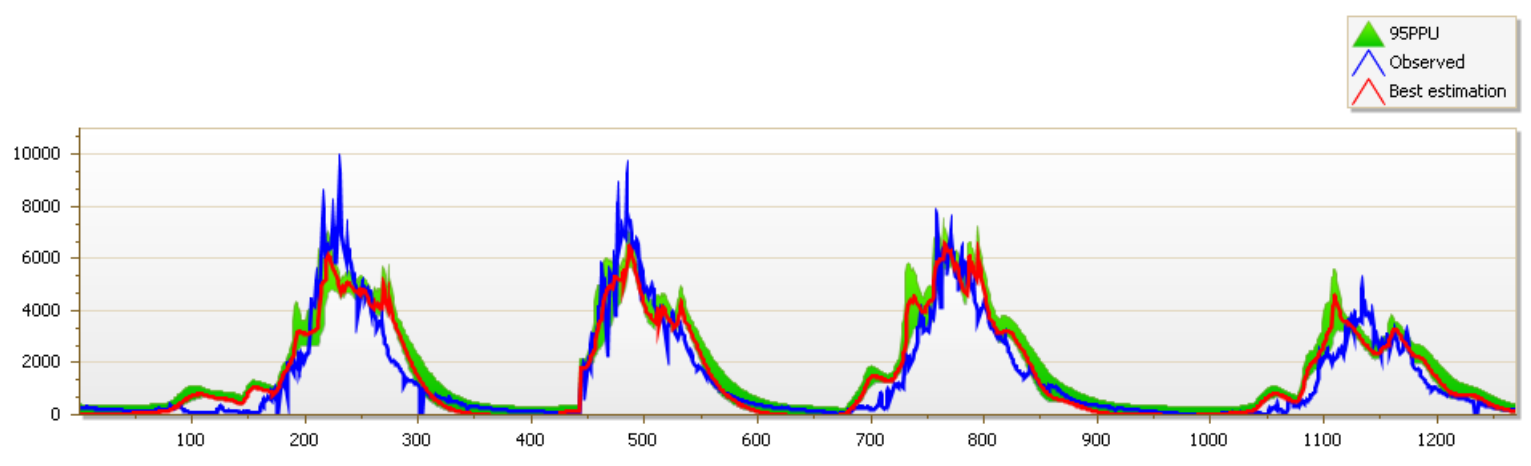

Iteration 8 was taken as the final result for automatic calibration using SUFI2. Figure 7 shows that the model is still underestimating high flows at some time period. However, this iteration gave us a satisfactory NSE value of 0.87 , which represents the good performance of the model. This can 
be proved visually also as the simulated outflow is more or less similar with the observed outflow. Final parameter values obtained after the automatic calibration is represented in Table 4.

Table 4: Final parameter values for automatic calibration

\begin{tabular}{|c|c|}
\hline Parameter & Calibrated Value \\
\hline CN2 & 0.11 \\
\hline Alpha_BF & 0.19 \\
\hline GW_DELAY & 93.93 \\
\hline GWQMN & 4545.50 \\
\hline CH_K2 & 133.88 \\
\hline ESCO & 0.68 \\
\hline GW_REVAP & 0.15 \\
\hline RCHRG DP & 0.00 \\
\hline SOL_AWC & 0.00 \\
\hline SOL K & -0.43 \\
\hline
\end{tabular}

\subsubsection{Automatic Validation Results}

Validation was again performed as a next step to check whether the model can predict uncertainty for five years simulation period of 1974-1978 including one year as warm up period.

Figure 8: Automatic validation result

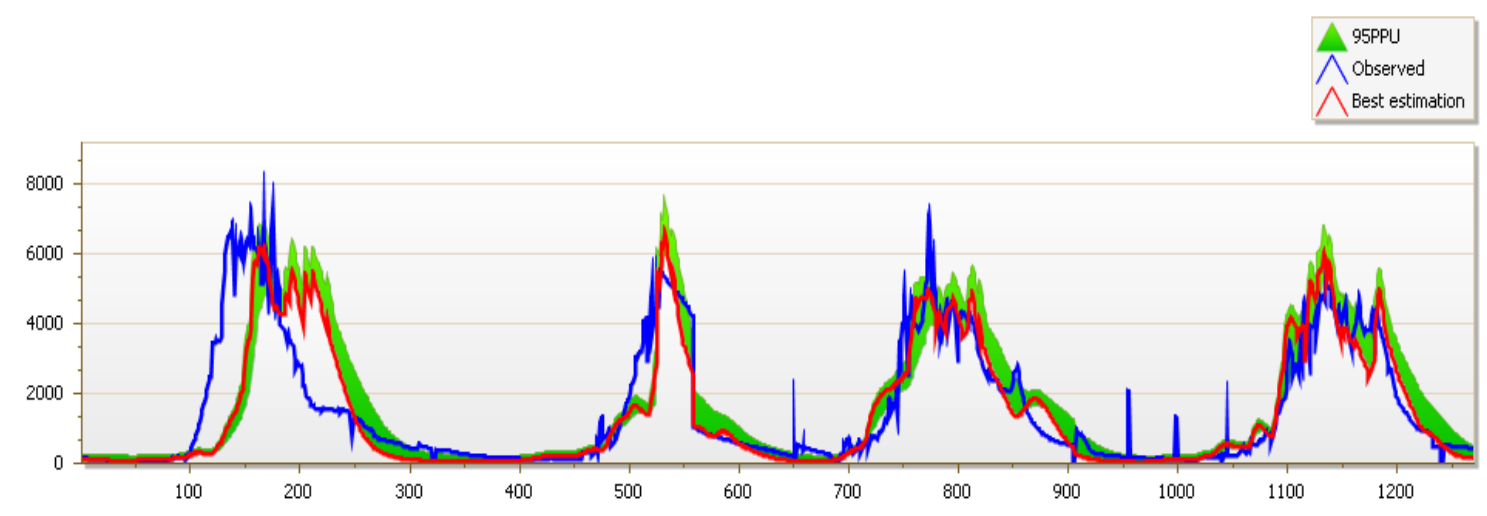

The result gave an NSE of 0.66 which indicates good performance of model however visually we can see that the model is underestimating high flows for first event and the simulated flows are also lagged forward.

\subsection{Model Evaluation}

Model evaluation is considered as an important step in model development process. In order to determine whether or not a model is capable to obtain prediction close to observed data and to determine which best model for our data, one need to have a quality check benchmark. 


\subsubsection{Performance Indexes:}

Although statistical data are interpreted visually also, NSE objective function is used as a measure to check goodness of fit for outflow from the catchment. NSE is a dimensionless value which shows goodness of fit between observed and simulated data. It ranges from - $\infty$ to 1 with 1 being the model with acceptable range of uncertainty and NSE values of 0.54-0.64 are adequate and any values greater than 0.5 are satisfactory (D. N. Moriasi et al., 2007).

Table 5: Performance indexes for manual calibration

\begin{tabular}{|c|c|c|c|}
\hline Iteration & NSE & Iteration & NSE \\
\hline Default & -5.82 & 5 & 0.25 \\
\hline 1 & -3.50 & 6 & 0.47 \\
\hline 2 & -3.99 & 7 & 0.58 \\
\hline 3 & -1.37 & 8 & 0.71 \\
\hline 4 & -0.90 & & \\
\hline
\end{tabular}

From Table 5, we can see that the model result was improved in each iteration and the final iteration 8 with an NSE value of 0.71 shows that model performance is good. As the manual calibration is tedious and less accurate, automatic calibration was done to obtain more precise result.

Table 6: Performances indexes for automatic calibration

\begin{tabular}{|l|l|l|l|}
\hline Iteration & NSE & Iteration & NSE \\
\hline 1 & 0.08 & 5 & 0.85 \\
\hline 2 & 0.33 & 6 & 0.86 \\
\hline 3 & 0.53 & 7 & 0.86 \\
\hline 4 & 0.8 & 8 & 0.87 \\
\hline
\end{tabular}

The iteration 8 yields the best model result with an NSE of 0.87 which shows good performance of the model (Table 6). This can be proved with another index $\mathrm{R}^{2}$ which has a value of 0.87 (closer to 1) describes good proportion of variance of measured data. The p-factor of 0.7 represents that $70 \%$ of the observations are covered in $95 \%$ of uncertainty and r-factor of 0.36 represents the thickness of 95PPU band divided by standard deviation of measured data which is close to 0 . Hence, we can say that the model is able to predict uncertainty more precisely in automatic calibration.

As the model calibration was good based on evaluation criteria, model validation was again done to check whether the model can predict flows accurately for a time period of 1974-1978 (one-year skip) than those for which the model was calibrated. 
Table 7: Performances indexes for validation

\begin{tabular}{|c|c|}
\hline Calibration & NSE \\
\hline Manual & 0.63 \\
\hline Automatic & 0.66 \\
\hline
\end{tabular}

From Table7, it is visible that in case of manual and automatic validation, NSE shows a satisfactory performance result. NSE values were more accurate in automatic validation.

\section{Conclusion and Recommendations}

While surface water modelling is indispensable for making basin management decisions including flood/drought forecasting and preparedness, we should be aware that no model can be a perfect model which represents the physical reality of nature exactly as it is because of possibilities of uncertainties in data, calibration parameters as well as the model structure. The SWAT model in this exercise overestimated and then underestimated the flow for automatic calibration and validation respectively. The following deliberates on the possible reasons for the disaccord between simulated and observed flows and recommendations to remedy them:

1. To decrease complexities in calibration, the model was built up with 299 HRUs which reduces the spatial variability of the physical components like land cover, soil and slope of the catchment. Increasing the number of HRUs could enhance model performance in the expense of higher computation time.

2. Around $15 \%$ of observed data in both calibration and validation were missing in this exercise. These missing values were eliminated to form a continuous time series. Because of this, there is a possibility that with the complete time series, the corresponding parts of observed and simulated hydrograph for every rainfall event would be considered which could potentially increase the goodness of fit of the statistical indicator values.

3. The major parameters affecting the hydrological processes were taken into consideration in this exercise and were juxtaposed with available literature about Blue Nile basin online wherever possible. However, SWAT's copious nature of parameters meant there were lot of parameters that were not modelled in this exercise. A broader utilization of parameters could also enhance the performance of the model.

4. The temporal variability between meteorological data and remote sensing data could intimate that the given remote sensing data, like land cover for instance, might not be representative of the actual conditions for the duration of time whose meteorological data are being used. Factors such as urbanization, land use changes have potential to significantly alter the land cover map of any area. Reducing the temporal variability could result in better model performance too.

Besides these, there are other aspects, which could be considered to improve the performance of the model. Increasing the calibration duration could consider extreme events as well, which would result in increased predictability of the model with regards to extreme events. Further, flow data from additional stations within the catchment could be used for calibration in order to improve the accuracy of the model. 


\section{Acknowledgment}

We would like to reflect on the people who have helped me in one way or other way to complete this paper. A special thanks goes to Professor Ann Van Griensven who gave us insight regarding surface water modelling. We are also grateful to her for giving us the permission to use the data of Upper Blue Nile basin. We appreciate the VLIR-UOS (Vlaamse Interuniversitaire RaadUniversity Development Cooperation) who sponsored our master study and fulfilling our dream to pursue higher studies. We would like to thank IUPWARE for developing a program where students are inspired to be passionate regarding their work and the professors are always eager and happy to see their students succeed.

\section{References}

[1] A. van Griensven, P. Ndomba, F. Kilonzo, \& S. Yalew. (2012). "Critical review of SWAT applications in the upper Nile basin countries". Hydrology and Earth System Sciences, Vol. 16, pp. 3371-3381.

[2] Abbaspour, K. C., Yang, J., Maximov, I., Siber, R., Bogner, K., Mieleitner, J., Srinivasan, R. (2007). "Modelling hydrology and water quality in the pre-alpine/alpine Thur watershed using SWAT". Journal of Hydrology, vol. 333(2), pp. 413-430.

[3] Abtew, W., Melesse, A. M., \& Dessalegne, T. (2009). "Spatial, inter and intra-annual variability of the Upper Blue Nile Basin rainfall”. Hydrological Processes, vol. 23, pp. 3075-3082.

[4] Ahl, R. S., Woods, S. W., \& Zuuring, H. R. (2008). "Hydrologic Calibration and Validation of SWAT in a Snow-Dominated Rocky Mountain Watershed, Montana, U.S.A. "'. JAWRA Journal of the American Water Resources Association, vol. 44, pp. 1411-1430.

[5] Amr Fleifle, Ralf Ludwig, \& Markus Disse. (2017). "Improving SWAT model performance in the upper Blue Nile Basin using meteorological data integration and subcatchment discretization”. Hydrology and Earth System Sciences, vol. 21, pp. 49074926.

[6] Brouziyne, Y., Abouabdillah, A., Bouabid, R., Benaabidate, L., \& Oueslati, O. (2017). "SWAT manual calibration and parameters sensitivity analysis in a semi-arid watershed in North-western Morocco". Arabian Journal of Geosciences, vol. 10, pp. $1-13$.

[7] Chu Xuefeng, \& Steinman Alan. (2009). "Event and Continuous Hydrologic Modeling with HEC-HMS". Journal of Irrigation and Drainage Engineering, vol. 135(1), pp. 119124.

[8] Conway, D. (2000). "The Climate and Hydrology of the Upper Blue Nile River". The Geographical Journal, vol. 166(1), pp. 49-62.

[9] Conway, D. (Climatic R. U. (1997). "A water balance model of the Upper Blue Nile in Ethiopia”. Hydrological Sciences Journal, vol. 42, pp. 265-286. 
[10] D. N. Moriasi, J. G. Arnold, M. W. Van Liew, R. L. Bingner, R. D. Harmel, \& T. L. Veith. (2007). "Model Evaluation Guidelines for Systematic Quantification of Accuracy in Watershed Simulations". Transactions of the ASABE, vol. 50(3), pp. 885-900.

[11] Dile, Y. T., Tekleab, S., Ayana, E. K., Gebrehiwot, S. G., Worqlul, A. W., Bayabil, H. K.,Srinivasan, R. (2018). "Advances in water resources research in the Upper Blue Nile basin and the way forward: A review". Journal of Hydrology, vol. 560, pp. 407-423.

[12] El Bastawesy, M., Gabr, S., \& Mohamed, I. (2015). "Assessment of hydrological changes in the Nile River due to the construction of Renaissance Dam in Ethiopia". The Egyptian Journal of Remote Sensing and Space Science, vol. 18(1), pp. 65-75.

[13] Jha, M. K. (2011). "Evaluating Hydrologic Response of an Agricultural Watershed for Watershed Analysis". Water, vol. 3(2), pp. 604-617.

[13] Kim, U., \& Kaluarachchi, J. J. (2009). "Climate Change Impacts on Water Resources in the Upper Blue Nile River Basin, Ethiopial”. JAWRA Journal of the American Water Resources Association, vol. 45(6), pp. 1361-1378.

[15] Me, W., Abell, J. M., \& Hamilton, D. P. (2015). "Effects of hydrologic conditions on SWAT model performance and parameter sensitivity for a small, mixed land use catchment in New Zealand". Hydrology and Earth System Sciences; Katlenburg-Lindau, vol. 19(10), pp. 4127.

[16] Melesse, A. M., Abtew, W., Setegn, S. G., \& Dessalegne, T. (2011). Hydrological Variability and Climate of the Upper Blue Nile River Basin. In A. M. Melesse (Ed.), Nile River Basin: Hydrology, and Water Use,Springer Science publisher, Berlin, pp. 337.

[17] Nasr, A., Bruen, M., Jordan, P., Moles, R., Kiely, G., \& Byrne, P. (2007). “A comparison of SWAT, HSPF and SHETRAN/GOPC for modelling phosphorus export from three catchments in Ireland". Water Research, vol. 41(5), pp. 1065-1073.

[18] Mengistu, D., Bewket, W., \& Lal, R. (2014). "Recent spatiotemporal temperature and rainfall variability and trends over the Upper Blue Nile River Basin, Ethiopia". International Journal of Climatology, vol 34. pp. 2278-2292.

[19] Rostamian, R., Jaleh, A., Afyuni, M., Mousavi, S. F., Heidarpour, M., Jalalian, A., \& Abbaspour, K. C. (2008). "Application of a SWAT model for estimating runoff and sediment in two mountainous basins in central Iran". Hydrological Sciences Journal, vol. 53(5), pp. 977-988.

[20] Setegn, S. G., Srinivasan, R., \& Dargahi, B. (2008). Hydrological Modelling in the Lake Tana Basin, Ethiopia Using SWAT Model”. The Open Hydrology Journal, vol. 2(1). pp. 49-62.

[21] Tekleab, S., Mohamed, Y., \& Uhlenbrook, S. (2013). Hydro-climatic trends in the Abay/Upper Blue Nile basin, Ethiopia”. Physics and Chemistry of the Earth, Parts A/B/C, vol. 61-62, pp. 32-42.

[22] Thompson, J. R., Sørenson, H. R., Gavin, H., \& Refsgaard, A. (2004). Application of the coupled MIKE SHE/MIKE 11 modelling system to a lowland wet grassland in southeast England". Journal of Hydrology, vol. 293(1), pp. 151-179. 
[23] Van den Bergh, J., \& Roulin, E. (2016). Postprocessing of Medium Range Hydrological Ensemble Forecasts Making Use of Reforecasts". Hydrology, vol. 3(2), pp. 21.

[24] Walker, W. E., Harremoës, P., Rotmans, J., Sluijs, J. P. van der, Asselt, M. B. A. van, Janssen, P., \& Krauss, M. P. K. von. (2003). Defining Uncertainty: A Conceptual Basis for Uncertainty Management in Model-Based Decision Support". Integrated Assessment, vol. 4(1), pp. 5-17. 